\title{
Transgenic sickle cell disease mice have high mortality and dysregulated immune responses after vaccination
}

\author{
Steven M. Szczepanek', Eric R. Secor Jr², Sonali J. Bracken², Linda Guernsey², Ektor Rafti ${ }^{2}$, Adam Matson², Roger S. Thrall ${ }^{2}$ \\ and Biree Andemariam ${ }^{1}$
}

BACKGROUND: Children with sickle cell disease (SCD) are susceptible to recurrent infections, which are often life threatening and necessitate frequent vaccinations. Given the altered baseline immunity and proinflammatory state associated with $S C D$, we sought to determine the relative safety and efficacy of vaccination in transgenic SCD mice.

METHODS: Eight-week-old SCD mice were vaccinated with ovalbumin and aluminum hydroxide weekly for $3 w k$ by the intraperitoneal or intramuscular route. One week after the third vaccination, serum cytokines/chemokines, immunoglobulins, and bronchoalveolar lavage fluid cytokines were measured.

RESULTS: Only SCD mice were prone to mortality associated with vaccination, as $40 \%$ of the animals died after the intraperitoneal vaccinations and 50\% died after the intramuscular vaccinations. Serum IgG2b and IgM were significantly lower in SCD mice than in C57BL/6 mice after vaccination, but ovalbumin-specific lgE was significantly higher. Serum interleukin (IL)- $1 \alpha, I L-2, I L-5$, macrophage inflammatory protein $1 \alpha$, and granulocyte macrophage-colony stimulating factor were significantly lower in SCD mice than in C57BL/6 mice after vaccination, whereas bronchoalveolar lavage fluid IL-1 $\beta$ and IL-6 were increased.

CONCLUSION: Mice with SCD appear to have a dysregulated immune response to vaccination. Thus, the relative safety and immunogenicity of vaccination should be studied in greater detail in the context of SCD.

hildren suffering from sickle cell disease (SCD) are prone to frequent and severe infections that can lead to premature death if prompt antibiotic treatment is not administered. One of the most common infections in children with SCD is caused by Streptococcus pneumoniae, which often manifests as pneumonia and can lead to septicemia if the bacterium becomes invasive. The incidence of invasive $S$. pneumoniae infection in individuals with SCD is between 30- and 600-fold higher (depending on age) than what is observed in the general population (1). As a consequence, children with SCD typically adhere to strict vaccination schedules that often include more frequent booster shots than children without SCD. The introduction of pneumococcal vaccines has reduced the incidence of mortality associated with $S$. pneumoniae infection in children with SCD by $80-90 \%(2,3)$; however, infection in vaccinees has nevertheless been reported in this population (4). Vaccination against both S. pneumoniae and influenza A virus appears to result in low antigen-specific IgG and IgM antibody titers $(5,6)$, the latter of which is likely to be a consequence of a reduced number of IgM-producing B cells $(7,8)$. Furthermore, a recent study has shown an association between chronic transfusion of children with SCD and a lack of protective postvaccination antibody response to influenza A (9). Taken together, these findings bring into question the relative immunogenicity of vaccination in children with SCD as compared with control subjects and indicate that hyporesponsiveness to vaccine antigens may not be uncommon.

The phase I safety evaluations of vaccines are usually tested in the general population but are not tested in individuals with uncommon diseases such as SCD. The recently developed intranasal influenza vaccine (FluMist; MedImmune, Gaithersburg, $\mathrm{MD}$ ) is one such example and, consequently, administration of this vaccine to patients with $S C D$ is not recommended by the Centers for Disease Control. Even when a vaccine is routinely administered as part of the standard vaccination schedule, such as is the case with the trivalent-inactivated influenza vaccine, controversy may arise pertaining to its safety in people with uncommon diseases. Indeed, recent retrospective studies using the Vaccine Safety Datalink project have indicated that the trivalent-inactivated influenza vaccine is not associated with hospitalization in children or adults with $\operatorname{SCD}(10,11)$; however, a previous report by this group had shown that compared to control subjects, people with SCD had more frequent fever or pain episodes that resulted in an inpatient visit within 2 wk of influenza vaccination (12). To our knowledge, no published prospective studies have been conducted in humans or mice to definitively determine whether vaccination is associated with adverse effects in SCD.

Little work has been conducted in transgenic SCD mice to study the effects of experimental treatment on basic outcomes that cannot be tested in humans. One of the few papers to do so demonstrated that natural killer $\mathrm{T}$ cells are an important source of pulmonary dysfunction at baseline in NY1DD SCD 
mice (13). Another report used intraperitoneal injection of lipopolysaccharide into the "Berkeley" (Berk) transgenic SCD mouse strain to determine the effects of systemic challenge with an inflammatory agent on markers of disease (14). Many of these mice died shortly after injection, and the survivors exhibited negative respiratory outcomes and had increased inflammatory markers. In another study, experimental asthma was induced in SCD mice by subcutaneous implantation of ovalbumin (OVA), followed by OVA aerosol challenge (15). Mortality of SCD mice was associated with subcutaneous implantation of OVA, and marked increases in IgE were observed. A follow-up study by the same group also demonstrated increases in bronchoalveolar lavage (BAL) cytokines (including interleukin (IL)-1 $\beta$ and IL-6) after the induction of asthma in SCD mice (16). Taken together, these findings indicate that SCD results in exaggerated inflammatory responses in reaction to antigenic stimuli.

There appears to be a dichotomy in SCD between hyporesponsiveness to some antigens and an overzealous inflammatory response to others. Our original goal was to study asthma in a murine model of SCD using our previously published intraperitoneal OVA/aluminum hydroxide (alum) vaccination/ sensitization protocol (17). However, upon experiencing 50\% mortality with sensitization alone in multiple experiments, we shifted focus toward understanding how transgenic SCD mice respond to vaccination. Herein, we describe changes in systemic and pulmonary cytokines, serum antibodies, and antigen-specific IgE responses in SCD mice that survived vaccination as compared with wild-type and hemizygous mice. Implications for infection and vaccination in children with SCD are discussed.

\section{RESULTS}

\section{Vaccination-Induced Mortality}

Intraperitoneal vaccination of SCD mice with the protein antigen OVA and adjuvant alum resulted in significant mortality (40\%) as compared with either C57BL/6 or hemizygous mice (no deaths in either group; $P<0.05$; Figure 1). This effect occurred with increasing frequency at each additional intraperitoneal injection. In order to validate that the route of inoculation was not the major factor of SCD mouse mortality, additional mice were inoculated with OVA/alum via the intramuscular route. Again, only SCD mice died after the injections (50\%), which was significantly different from C57BL/6 and hemizygous mice. Interestingly, the kinetics of mortality were different between the two routes of inoculation, with intraperitoneal injection resulting in the greatest mortality after the third vaccination and intramuscular injection resulting in mortality after only one vaccination.

\section{Antibody Responses}

Concentrations of postvaccination serum immunoglobulin class and subclasses were measured $1 \mathrm{wk}$ after the third vaccination using a Luminex assay. As compared with C57BL/6 mice, SCD mice exhibited significantly lower serum concentrations of IgG2b (Figure 2a). Serum concentrations of

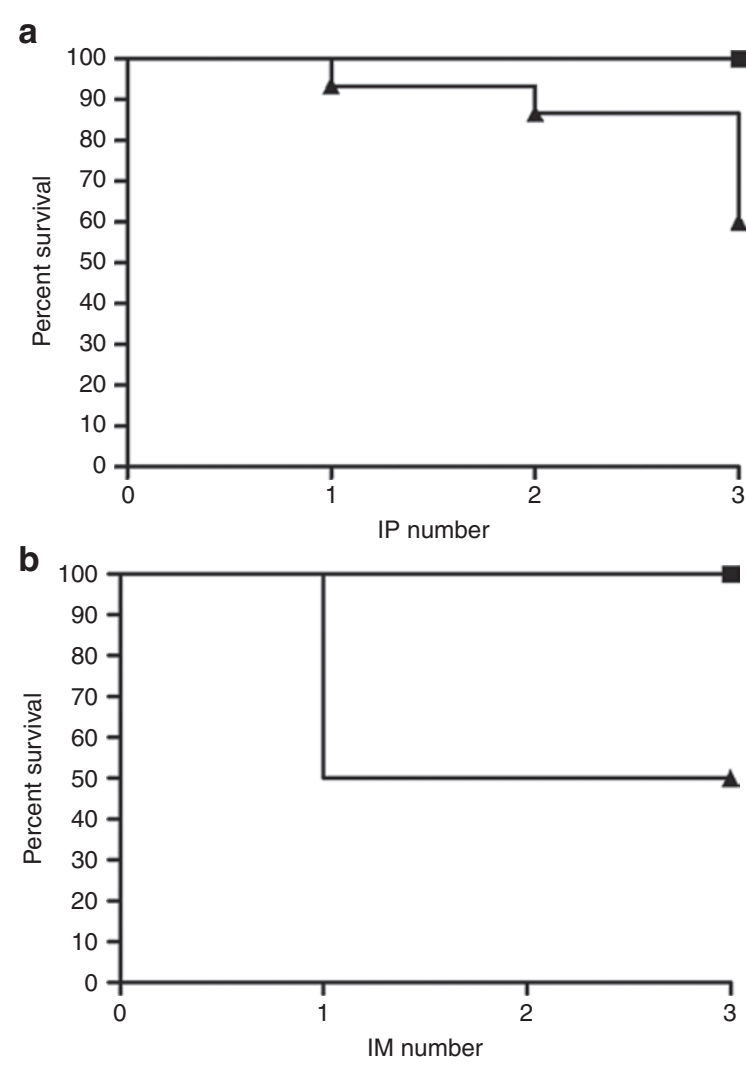

Figure 1. Postvaccination Kaplan-Meier survival curves. (a) Percentage survival of C57BL/6 $(n=11)$, hemizygous $(n=11)$, or sickle cell disease (SCD) mice ( $n=15)$ after each intraperitoneal (IP) vaccination. (b) Percentage survival of C57BI/6 $(n=6)$, hemizygous $(n=7)$, or SCD mice $(n=6)$ after each intramuscular (IM) vaccination. Curves for SCD mice for both routes of inoculation were significantly different from C57BL/ 6 and hemizyous mice $(P<0.05)$. Closed squares $=$ C57BL6 and hemizygous mice; closed triangles $=S C D$.

IgM were also significantly reduced in SCD mice. No differences were observed in any postvaccination Ig class/subclass between SCD and hemizygous mice. When comparing pre- vs. postvaccination serum antibody levels, dramatically higher fold-change increases were observed for IgG2b in C57BL/6 mice than in SCD mice, indicating that the lower level of this Ig subclass postvaccination is attributable to an inability of SCD mice to produce it in response to vaccination (Figure 2b). No difference in the fold change of IgM concentrations in the pre- vs. postvaccination samples was observed among the groups (Figure $2 \mathrm{~b}$ ), which is likely to be due to the previously reported reduction of IgM at baseline in SCD mice (8). As compared with C57BL/6 mice, SCD mice exhibited dramatically increased OVA-specific IgE titers after vaccination (Figure 2c), indicating that SCD mice might be more prone to allergic sensitization than C57BL/6 mice. No difference was observed in OVA-specific IgE titers when SCD and hemizygous mice were compared.

\section{Cytokine/Chemokine Responses}

Concentrations of postvaccination serum cytokines and chemokines were measured $1 \mathrm{wk}$ after the third vaccination using 


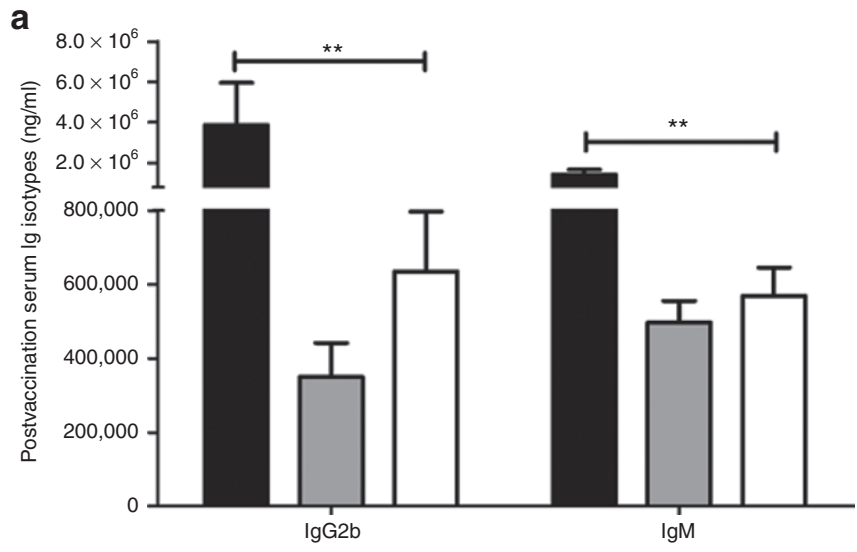

b

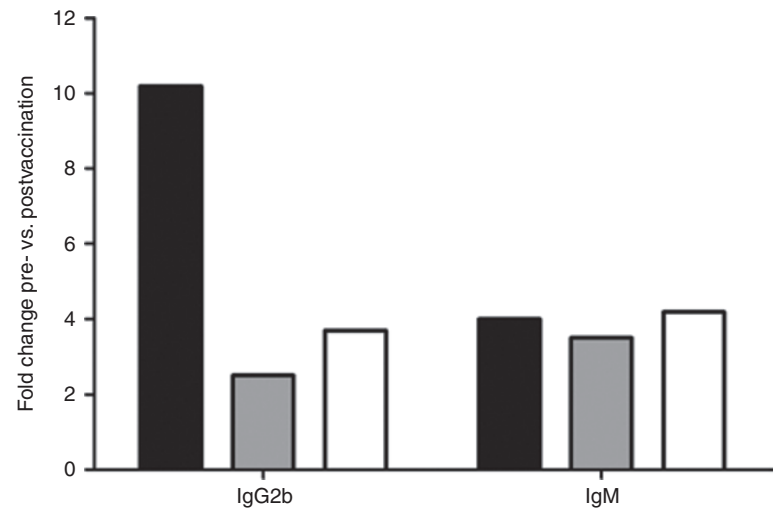

C

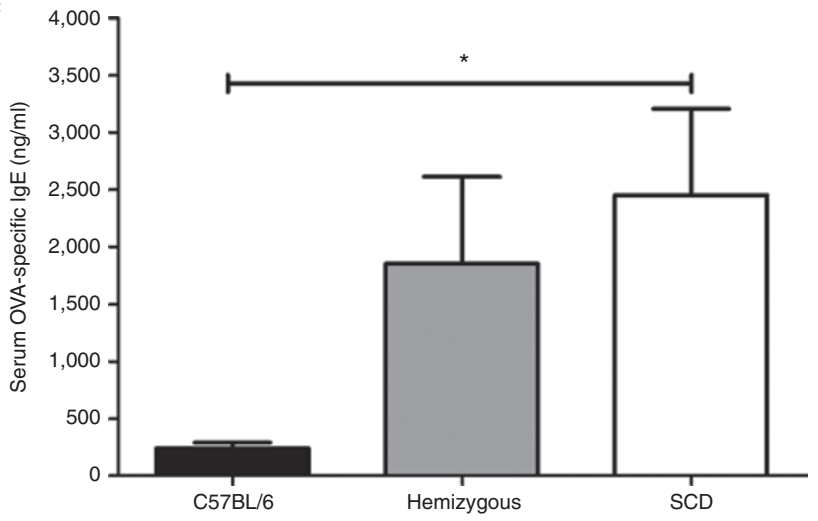

Figure 2. Serum antibody responses to vaccination. (a) Significantly different serum immunoglobulin concentrations postvaccination as measured by Luminex assay (lgG2b: C57BL/6 $=3.88 \times 10^{6} \mathrm{ng} / \mathrm{ml}$ (SEM: 2,072,000), hemizygous $=350,000 \mathrm{ng} / \mathrm{ml}$ (SEM: 92,000), sickle cell disease $(S C D)=635,000 \mathrm{ng} /$ $\mathrm{ml}(\mathrm{SEM}: 162,000) ; P<0.01)$ (IgM: C57BL/6 $=1.44 \times 10^{6} \mathrm{ng} / \mathrm{ml}$ (SEM: 244,000), hemizygous $=497,000 \mathrm{ng} / \mathrm{ml}$ (SEM: 59,000), SCD $=570,000 \mathrm{ng} / \mathrm{ml}$ (SEM: $75,000) ; P<0.001)$. (b) Pre- vs. postvaccination fold change in significantly different serum immunoglobulins postvaccination. (c) Serum concentrations of ovalbumin (OVA)-specific lgE antibodies as measured by enzymelinked immunosorbent assay (C57BL/6 $=242 \mathrm{ng} / \mathrm{ml}$ (SEM: 48), hemizygous $=1,854 \mathrm{ng} / \mathrm{ml}$ (SEM: 758), SCD = 2,452 ng $/ \mathrm{ml}(\mathrm{SEM}: 754) ; P<0.05)$. Bars represent mean levels \pm SEM. Significant differences were determined by one-way ANOVA, and pairwise comparisons were conducted using the Dunnett's post hoc test with SCD serving as the control group. Black bars = C57BL/6; gray bars $=$ hemizygous; white bars $=\mathrm{SCD} .{ }^{*} P<0.05,{ }^{* *} P<0.01$.

a Luminex assay. As compared with C57BL/6 mice, SCD mice had lower serum concentrations of the cytokines IL-1 $\alpha$, IL-2, and IL-5 (Figure 3a). Reduced concentrations of the serum chemokines macrophage inflammatory protein $1 \alpha$ (MIP- $1 \alpha)$ and granulocyte macrophage-colony stimulating factor were also found. No significant differences in the aforementioned cytokines/chemokines were measured between SCD and hemizygous mice. When comparing pre- vs. postvaccination cytokine levels, fold-change differences in IL-1 $\alpha$ were not noticeably different among the groups (Figure $3 \mathbf{b}$ ), which is likely to be due to the previously reported reduction of this cytokine at baseline in SCD mice (8). Dramatically higher pre- vs. postvaccination fold-change increases were observed for both IL-2 and granulocyte macrophage-colony stimulating factor in C57BL/6 mice compared to SCD mice, indicating that the lower levels of these cytokines postvaccination is attributed to an inability of SCD mice to produce them in response to vaccination. Moreover, when pre- vs. postvaccination titers were compared, SCD mice exhibited reduced levels of MIP- $1 \alpha$. This indicates that SCD mice have a severely dysregulated MIP-1 $\alpha$ response after vaccination.

Several serum cytokines were significantly increased in response to vaccination in $\mathrm{C} 57 \mathrm{BL} / 6$ mice, but not in SCD or hemizygous mice (Figure $3 \mathrm{c}$ ). These cytokines include IL-1 $\beta$, IL-7, IL-12 (p70), and IL-17. These cytokines exhibited more variability within groups, thereby contributing to a lack of significance when postvaccination concentrations were compared. However, SCD mice (and hemizygous mice) appear to have a reduced ability to produce these cytokines in response to vaccination. Taken together, SCD mice that survive inoculation appear to be hyporesponsive to vaccination, as demonstrated by their lack of cytokine production in serum postvaccination.

In contrast to the hyporesponsiveness exhibited by SCD mice in the production of serum cytokines after vaccination, cytokines in BAL fluid appeared to be higher in SCD mice (Figure 4). BAL fluid IL-1 $\beta$ was not measurable in C57BL/6 mice postvaccination (minimum detection limit = $0.20 \mathrm{pg} / \mathrm{ml}$ ) and was significantly higher in SCD mice as compared with either hemizygous mice or C57BL/6 mice. Similarly, IL- 6 was increased in the BAL fluid of SCD mice as compared with C57BL/6 mice (not measurable, minimum detection limit $=0.28 \mathrm{pg} / \mathrm{ml}$ ) after vaccination. No differences in postvaccination BAL fluid IL- 6 were observed between hemizygous mice and SCD mice.

\section{DISCUSSION}

Relative safety and immunogenicity are important features to consider when administering vaccines, yet these two basic parameters are not well understood in children with uncommon diseases such as SCD. Death of SCD mice after injection of inflammatory agents is a phenomenon that has been known for some time and is presumably associated with heightened baseline inflammation. A previous study showed that intraperitoneal inoculation with the proinflammatory molecule lipopolysaccharide resulted in $\sim 60 \%$ mortality of SCD mice, whereas sham inoculation with saline had no effect (14). Protein antigens may also produce mortality in SCD mice, as has been shown by subcutaneous implantation of OVA (15). 
a
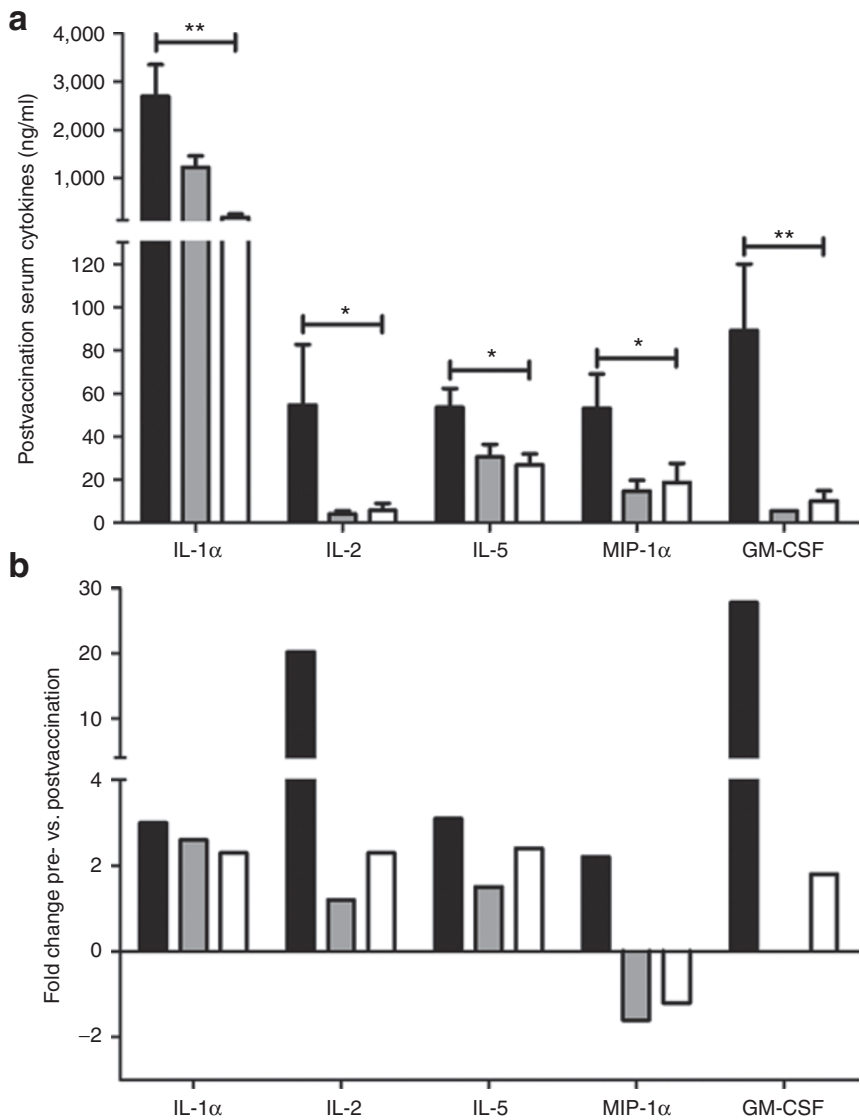

C

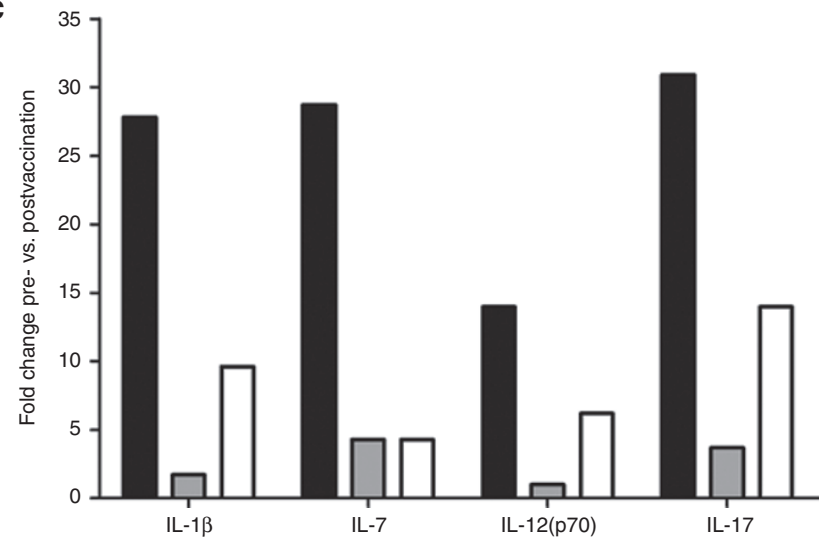

Figure 3. Serum cytokine and chemokine responses to vaccination. (a) Significantly different postvaccination cytokine/chemokine serum concentrations as measured by Luminex assay (interleukin (IL)- $1 \alpha$ : $\mathrm{C} 57 \mathrm{BL} / 6=2,692$ $\mathrm{pg} / \mathrm{ml}$ (SEM: 659), hemizygous $=1,224 \mathrm{pg} / \mathrm{ml}$ (SEM: 236), sickle cell disease $(\mathrm{SCD})=195 \mathrm{pg} / \mathrm{ml}(\mathrm{SEM}: 64) ; P<0.001)($ IL-2: C57BL/6 $=55 \mathrm{pg} / \mathrm{ml}$ (SEM: 28), hemizygous $=4.2 \mathrm{pg} / \mathrm{ml}$ (SEM: 1.4$), \mathrm{SCD}=5.8 \mathrm{pg} / \mathrm{ml}($ SEM: 3.2$) ; P<0.05)$ (IL-5: C57BL/6 = 54 (SEM: 8.7), hemizygous $=31$ pg/ml (SEM: 5.8), SCD = 27 $\mathrm{pg} / \mathrm{ml}$ (SEM: 5.2); $P<0.05$ ) (macrophage inflammatory protein $1 \alpha$ (MIP$1 \alpha): C 57 B L / 6=53 \mathrm{pg} / \mathrm{ml}$ (SEM: 16), hemizygous $=15 \mathrm{pg} / \mathrm{ml}$ (SEM: 4.9), SCD = $19 \mathrm{pg} / \mathrm{ml}$ (SEM: 8.8); $P<0.05$ ) (granulocyte macrophage-colony stimulating factor (GM-CSF): C57BL/6 $=89 \mathrm{pg} / \mathrm{ml}$ (SEM: 31), hemizygous $=5.5 \mathrm{pg} / \mathrm{ml}$ (SEM: NA), SCD = $10 \mathrm{pg} / \mathrm{ml}$ (SEM: 4.7); $P<0.01$ ). (b) Pre- vs. postvaccination fold change in significantly different postvaccination serum cytokines/ chemokines. (c) Fold change in serum cytokines that were only significantly different pre- vs. postvaccination in C57BL/6 mice. Bars represent mean levels \pm SEM. Significant differences were determined by one-way ANOVA and pairwise comparisons were conducted using the Dunnett's post hoc test with SCD serving as the control group. Black bars = C57BL/6; gray bars = hemizygous; white bars $=\mathrm{SCD} .{ }^{*} P<0.05,{ }^{* *} P<0.01$. NA, not applicable.

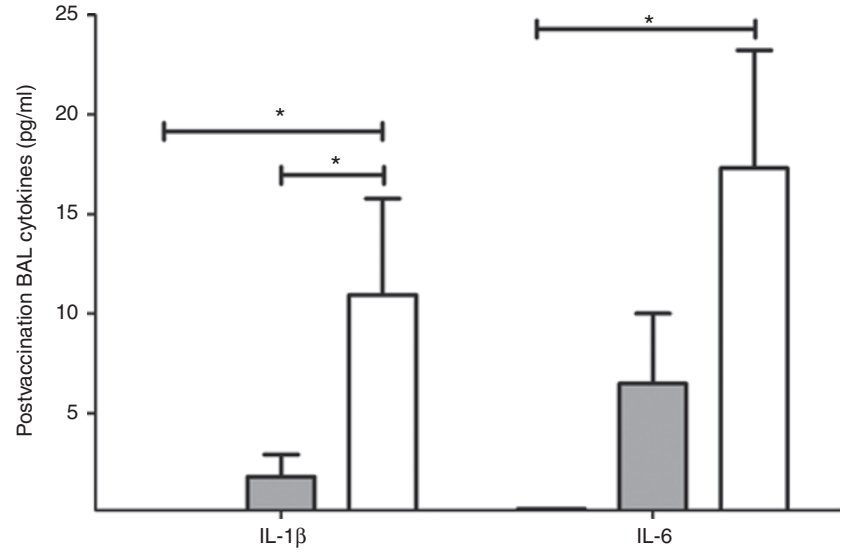

Figure 4. Bronchoalveolar lavage (BAL) fluid cytokines measured in response to vaccination. No cytokines were detected above the minimum detection limit (MDL) before vaccination (interleukin (IL)-1 $13:$ C57BL/ $6<$ $0.20 \mathrm{pg} / \mathrm{ml}$, hemizygous $=1.8 \mathrm{pg} / \mathrm{ml}$ (SEM: 1.1$)$, sickle cell disease $(\mathrm{SCD})=$ $11 \mathrm{pg} / \mathrm{ml}$ (SEM: 4.9); $P<0.05$ ) (IL-6: C57BL/ $6<0.28 \mathrm{pg} / \mathrm{ml}$, hemizygous $=6.5$ $\mathrm{pg} / \mathrm{ml}$ (SEM: 3.5), SCD = $17 \mathrm{pg} / \mathrm{I}$ (SEM: 5.9); $P<0.05$ ). Bars represent mean levels \pm SEM. Significant differences were determined by one-way ANOVA, and pairwise comparisons were conducted utilizing the Dunnett's post hoc test with $\mathrm{SCD}$ serving as the control group. Black bars $=\mathrm{C} 57 \mathrm{BL} / 6$; gray bars $=$ hemizygous; white bars $=\mathrm{SCD} .{ }^{*} P<0.05$.

Our findings of $\sim 40 \%$ mortality in SCD mice after intraperitoneal OVA/alum injection and 50\% mortality after intramuscular OVA/alum injection correlate with these previous reports. Thus, our model of vaccination has clinical implications pertaining to possible adverse events associated with vaccination of children with SCD.

The gold standard of immunogenicity for most vaccines is elicitation of the production of antigen-specific serum antibodies. As previously mentioned, SCD mice that survived vaccination had significantly higher OVA-specific IgE antibody serum concentrations than $\mathrm{C} 57 \mathrm{BL} / 6$ mice, indicating that these animals may be especially prone to allergic sensitization. Conversely, these same mice were hyporesponsive in terms of IgG2b and IgM production after vaccination. All groups of mice increased their IgM titers fourfold in response to vaccination, which indicates that differences in postvaccination IgM concentrations are due to low baseline production of this immunoglobulin. However, SCD mice induced only a fourfold increase in IgG2b after vaccination, whereas C57BL/6 mice increased serum concentrations more than tenfold. The inability of SCD mice to induce wild-type levels of IgG2b antibodies has potential clinical implications, as murine IgG2b is similar to human IgG3 (and to some degree IgG1) (18), with the ability to fix complement and bind to protein antigens. It is crucially important for vaccines to induce these functions for maximum efficacy. These findings are also in line with the observation that children living with SCD have diminished antibody responses to the hepatitis $B$ vaccine (19). Taken together, these findings have translational implications that should be investigated further in children living with SCD.

The ability of lymphocytes to become activated and proliferate in response to stimuli is essential for vaccine immunogenicity. Cytokines such as IL-2, IL-7, and IL-12 are responsible 
for allowing lymphocytes to mature/differentiate, proliferate, and generate immunological memory. The reduced postvaccination serum concentrations and apparent inability of these cytokines to be sufficiently stimulated after vaccination indicate that lymphocytes in SCD mice surviving vaccination may have subpar effectiveness or subpar memory functions. Furthermore, the chemokines MIP- $1 \alpha$ and granulocyte macrophage-colony stimulating factor, which are important for stimulating (20) and mobilizing (21) antigen-presenting cells (APCs) in response to antigen, are not produced at wild-type levels by SCD mice following vaccination. In fact, MIP- $1 \alpha$ appears to be downregulated in response to vaccination in SCD mice. This has serious implications, as MIP- $1 \alpha$ is important for the mobilization of dendritic cell precursors into the blood (22). MIP-1 $\alpha$ is also a ligand for CC chemokine receptor 5 (CCR5), which has been shown to be important for protection from pathogens such as influenza (23). Furthermore, it has been reported that there is a higher proportion of patients with SCD in Brazil who also have the CCR5D32-mutant allele as compared with controls (24). Extrapolation of our results from the mouse model then indicates that these individuals may mount suboptimal immune responses to vaccination, which may then leave them more susceptible to infection. SCD mice are also hyporesponsive to IL-17 production postvaccination, and this cytokine is important for clearance of mucosal bacterial pathogens. Indeed, protection of mice from $S$. pneumoniae colonization appears to be IL-17-dependent (25), which suggests that lack of IL-17 production in SCD mice may contribute to their increased susceptibility to pneumococcal infection (26).

Mouse models of acute lung injury are associated with increased levels of tumor necrosis factor- $\alpha$, IL- $1 \beta$, and IL- 6 in BAL fluid. This milieu has been shown to increase the production of secretory IgA in the lungs to help protect from infection when the natural barrier defenses are weakened (27). SCD mice that survived vaccination had significantly increased IL-1 $\beta$ and IL- 6 in their BAL fluid $1 \mathrm{wk}$ after the third vaccination as compared with $\mathrm{C} 57 \mathrm{BL} / 6$ mice, indicating that lung injury associated with vaccination had occurred. Given the long time between inoculation and measurement of these cytokines, it would not be surprising if they were in fact higher in concentration in the lung airways at earlier time points. It would not be surprising if tumor necrosis factor- $\alpha$ is increased early on as well. A study of acute lung injury in SCD mice also showed increased IL-6 in BAL fluid within hours of lipopolysaccharide injection (14), which corroborates our findings. The finding of increased IL-1 $\beta$ in BAL fluid of SCD mice that survived vaccination also has clinical implications, as this cytokine has been associated with ischemic reperfusion injury in human SCD (28), which is also associated with acute chest syndrome. Thus, therapeutics targeting IL- 6 and IL- $1 \beta$ may help to reduce pulmonary-related morbidity and mortality in people living with SCD.

Vaccination-related death of SCD mice raises the question of by what mechanism these animals are dying. This study does not directly address this question, as all outcomes were measured $1 \mathrm{wk}$ after the third vaccination only in animals that tolerated the OVA/alum inoculation. However, we were able to determine that the SCD mice that tolerated intraperitoneal vaccination and the hemizygous controls had similarly high levels of antigen-specific serum $\operatorname{IgE}$, and these levels were much higher than those found in C57BL/6 mice. This raises the possibility that the sensitive SCD mice may have had even higher IgE levels and died of shock from a type I hypersensitivity reaction. Anecdotal support of this hypothesis comes from the observation that all SCD mice that died after vaccination were found dead within hours of OVA/alum injection. Furthermore, all but one SCD mouse died after the second or third intraperitoneal injection, indicating that the mice had to be first sensitized to OVA/alum before they became susceptible to death from vaccination. Interestingly, susceptible SCD mice that were inoculated by the intramuscular route all died after the first vaccination, indicating that these mice did not have to be sensitized to antigen to be susceptible to death associated with this route of vaccination. It therefore seems likely that these animals died from an exaggerated inflammatory response, possibly driven by the presence of the adjuvant alum. Although we do not know the cause of the vaccination-related death of SCD mice, it is likely to be a combination of multiple etiologies that might include hypersensitivity reactions and exaggerated inflammatory responses. Further work is needed in order to more definitively answer this question.

Many studies have shown that both humans and mice with SCD live in an immunologically altered state. The study presented herein demonstrates that SCD mice are prone to death associated with vaccination, which is likely to be linked to the altered baseline immunity observed in these animals. Consequently, animals that survive inoculation appear to have dysregulated systemic immune responses to vaccination. Enhanced pulmonary production of IL- $1 \beta$ and IL- 6 suggests that acute lung injury may develop as a consequence of antigenic challenge. Our data suggest that the relative safety and immunogenicity of vaccination should be studied in greater detail in the context of SCD. Although it is clear that humans with SCD do not suffer mortality as a consequence of vaccination, there may be subclinical deleterious consequences that warrant further investigation.

\section{METHODS}

\section{Mice}

The animals used in this study have been previously described (8). Briefly, female mice, $\sim 8 \mathrm{wk}$ old, weighing $15-25 \mathrm{~g}$ each, were purchased from the Jackson Laboratory (Bar Harbor, ME). Berkeley sickle cell transgenic mice (Tg(Hu-miniLCR $\left.\alpha 1 \mathrm{G} \gamma \mathrm{A} \gamma \delta \beta \mathrm{S}) \mathrm{Hba}^{-/-} \mathrm{Hbb}^{-/-}\right)$ expressing human $H B A$ and $H B B^{S}$ and no longer expressing mouse $H b a$ and $H b b$ were used as a murine model of SCD. The stock background of this strain is a mixture of FVB/N, 129, DBA/2, Black Swiss, and $>50 \% \mathrm{C} 57 \mathrm{BL} / 6$ genomes. It was backcrossed to $\mathrm{C} 57 \mathrm{BL} / 6$, one generation after importation to The Jackson Laboratory. Hemizygous controls of the Berkeley transgenic SCD mouse (generated on the same mixed background of strains) that express no mouse $\mathrm{Hba}$, but do express one copy of mouse $H b b$, human $H B A$ and $H B B^{S}$, giving rise to a hemizygous genotype, were used as a second control arm. All mice were conventionally housed in plastic cages with corncob bedding. The housing facility was maintained at $22-24^{\circ} \mathrm{C}$ with a $12-\mathrm{h}$ 
light/dark cycle. Chow and water were given ad libitum. The Animal Care Committee at the University of Connecticut Health Center approved all mouse experiments.

\section{Vaccinations}

Mice were vaccinated by either the intraperitoneal or intramuscular route once per week for $3 \mathrm{wk}$. A suspension of $25 \mu \mathrm{g}$ of OVA (grade V; Sigma Chemical, St Louis, MO) with $2 \mathrm{mg}$ of alum in $500 \mu \mathrm{l}$ of saline was used for intraperitoneal inoculations, whereas a final volume of $50 \mu \mathrm{l}$ was used for intramuscular inoculations (one and a half dose injection into each hind limb).

\section{Collection of Serum and BAL Fluid}

One week after the third injection, mice were humanely killed with an overdose of ketamine/xylazine, and whole blood was immediately collected via cardiac puncture and placed into nonheparinized tubes for serum purification. Blood was allowed to clot at room temperature for $\sim 30-60 \mathrm{~min}$ and then spun for $10 \mathrm{~min}$ at $4,000 \mathrm{rpm}$ in an Eppendorf $5415 \mathrm{C}$ centrifuge (Eppendorf, Hauppauge, NY). Serum was then aliquoted and stored at $-80{ }^{\circ} \mathrm{C}$ until used. After killing, a BAL was performed on mouse lungs with five $1 \mathrm{ml}$ aliquots of physiologic saline. The BAL was then centrifuged at $1,700 \mathrm{~g}$ using a Thermo Scientific Sorvall ST 40R centrifuge (Thermo Scientific, Asheville, NC) with a swinging bucket rotor, and the supernatant (BAL fluid) was removed and concentrated $\times 10$ using Amicon Centriplus YM-10 filtration devices (Millipore, Bedford, MA), per the manufacturer's instructions. BAL fluid samples were stored at $-80^{\circ} \mathrm{C}$ until used.

\section{Analysis of Cytokines and Antibodies Using Luminex Assays}

Analysis of serum chemokines/cytokines and antibody class/subclass were conducted using Milliplex kits (Millipore), as previously described (8). Cytokines were analyzed using a 1:2 dilution, whereas immunoglobulins were analyzed at a 1:25,000 dilution (concentrations were adjusted to account for dilution). Serum IgA fell below the detection limit at this dilution for all animals and was not considered for analysis. BAL fluid cytokines were processed and analyzed using the same technique as serum, but sterile phosphate-buffered saline was used as a diluent for the standard curve. For samples in which an analyte could not be detected above the minimum detection limit, surrogate values of 0.1 or 1 less than the minimum detection limit (depending on the number of significant figures used) were used. For BAL fluid samples, postassay sample concentration and limits of detection were reported, taking into consideration the $\times 10$ sample concentration before analysis. Fold-change values were calculated using data from naive animals published in a previous report (8). Calculations are performed on the basis of groups of $11 \mathrm{C} 57 \mathrm{BL} / 6$ mice, 11 hemizygous mice, and nine SCD mice.

\section{OVA-Specific Serum IgE Levels}

An OVA-specific sandwich enzyme-linked immunosorbent assay was used to measure serum levels of IgE, as has been previously described (29). Results were interpolated from a standard curve. Calculations are performed on the basis of groups of eight C57BL/6 mice, nine hemizygous mice, and eight SCD mice.

\section{Statistics}

Statistical comparisons between groups were made with oneway ANOVA, and pairwise comparisons were conducted using the Dunnett's post hoc test with SCD serving as the control group. Analyses were conducted using GraphPad Prism version 5 software (GraphPad software, San Diego, CA) unless no variance was recorded within a group, in which case JMP statistical software version 5.1 (SAS Institute, Cary, NC) was used. All data were expressed as means \pm SEM. Differences were considered significant if $P \leq 0.05$.

\section{STATEMENT OF FINANCIAL SUPPORT}

Connecticut Institute for Clinical and Translational Science (CICATS) Clinical and Translational Scholars K12 Award; Lea's Foundation for Leukemia Research; and National Institute of Allergy and Infectious Disease grant RO1 Al04357-11.

\section{REFERENCES}

1. Overturf GD. Infections and immunizations of children with sickle cell disease. Adv Pediatr Infect Dis 1999;14:191-218.

2. Adamkiewicz TV, Sarnaik S, Buchanan GR, et al. Invasive pneumococcal infections in children with sickle cell disease in the era of penicillin prophylaxis, antibiotic resistance, and 23-valent pneumococcal polysaccharide vaccination. J Pediatr 2003;143:438-44.

3. Halasa NB, Shankar SM, Talbot TR, et al. Incidence of invasive pneumococcal disease among individuals with sickle cell disease before and after the introduction of the pneumococcal conjugate vaccine. Clin Infect Dis 2007;44:1428-33.

4. McCavit TL, Quinn CT, Techasaensiri C, Rogers ZR. Increase in invasive Streptococcus pneumoniae infections in children with sickle cell disease since pneumococcal conjugate vaccine licensure. J Pediatr 2011;158:505-7.

5. Bjornson AB, Lobel JS. Direct evidence that decreased serum opsonization of Streptococcus pneumoniae via the alternative complement pathway in sickle cell disease is related to antibody deficiency. J Clin Invest 1987;79:388-98.

6. Ballester OF, Abdallah JM, Prasad AS. Impaired IgM antibody responses to an influenza virus vaccine in adults with sickle cell anemia. Am J Hematol 1985;20:409-12

7. Rautonen N, Martin NL, Rautonen J, Rooks Y, Mentzer WC, Wara DW. Low number of antibody producing cells in patients with sickle cell anemia. Immunol Lett 1992;34:207-11.

8. Szczepanek SM, McNamara JT, Secor ER Jr, et al. Splenic morphological changes are accompanied by altered baseline immunity in a mouse model of sickle-cell disease. Am J Pathol 2012;181:1725-34.

9. Purohit S, Alvarez O, O’Brien R, Andreansky S. Durable immune response to inactivated $\mathrm{H} 1 \mathrm{~N} 1$ vaccine is less likely in children with sickle cell anemia receiving chronic transfusions. Pediatr Blood Cancer 2012;59:1280-3.

10. Hambidge SJ, Ross C, McClure D, Glanz J; VSD team. Trivalent inactivated influenza vaccine is not associated with sickle cell hospitalizations in adults from a large cohort. Vaccine 2011;29:8179-81.

11. Hambidge SJ, Ross C, Glanz J, et al.; Vaccine Safety Datalink Team. Trivalent inactivated influenza vaccine is not associated with sickle cell crises in children. Pediatrics 2012;129:e54-9.

12. Hambidge SJ, Glanz JM, France EK, et al.; Vaccine Safety Datalink Team. Safety of trivalent inactivated influenza vaccine in children 6 to 23 months old. JAMA 2006;296:1990-7.

13. Wallace KL, Marshall MA, Ramos SI, et al. NKT cells mediate pulmonary inflammation and dysfunction in murine sickle cell disease through production of IFN-gamma and CXCR3 chemokines. Blood 2009;114:667-76.

14. Holtzclaw JD, Jack D, Aguayo SM, Eckman JR, Roman J, Hsu LL. Enhanced pulmonary and systemic response to endotoxin in transgenic sickle mice. Am J Respir Crit Care Med 2004;169:687-95.

15. Nandedkar SD, Feroah TR, Hutchins W, et al. Histopathology of experimentally induced asthma in a murine model of sickle cell disease. Blood 2008;112:2529-38.

16. Pritchard KA Jr, Feroah TR, Nandedkar SD, et al. Effects of experimental asthma on inflammation and lung mechanics in sickle cell mice. Am J Respir Cell Mol Biol 2012;46:389-96.

17. Secor ER, Carson WF, Singh A, et al. Oral bromelain attenuates inflammation in an ovalbumin-induced murine model of asthma. Evid Based Complement Alternat Med 2008;5:61-9.

18. Unkeless JC, Scigliano E, Freedman VH. Structure and function of human and murine receptors for IgG. Annu Rev Immunol 1988;6:251-81.

19. Hord J, Windsor B, Koehler M, Blatt J, Janosky J, Mirro J. Diminished antibody response to hepatitis B immunization in children with sickle cell disease. J Pediatr Hematol Oncol 2002;24:548-9.

20. Narni-Mancinelli E, Campisi L, Bassand D, et al. Memory CD8 ${ }^{+}$T cells mediate antibacterial immunity via CCL 3 activation of TNF/ $\mathrm{ROI}^{+}$phagocytes. J Exp Med 2007;204:2075-87.

21. Wanjalla CN, Goldstein EF, Wirblich C, Schnell MJ. A role for granulocytemacrophage colony-stimulating factor in the regulation of $\mathrm{CD} 8^{+} \mathrm{T}$ cell responses to rabies virus. Virology 2012;426:120-33. 
22. He S, Cao Q, Yoneyama H, Ge H, Zhang Y, Zhang Y. MIP-3 $\alpha$ and MIP- $1 \alpha$ rapidly mobilize dendritic cell precursors into the peripheral blood. J Leukoc Biol 2008;84:1549-56.

23. Dawson TC, Beck MA, Kuziel WA, Henderson F, Maeda N. Contrasting effects of CCR5 and CCR2 deficiency in the pulmonary inflammatory response to influenza A virus. Am J Pathol 2000; 156:1951-9.

24. Chies JA, Hutz MH. High frequency of the CCR5 $\Delta 32$ variant among individuals from an admixed Brazilian population with sickle cell anemia. Braz J Med Biol Res 2003;36:71-5.

25. Moffitt KL, Gierahn TM, Lu YJ, et al. $\mathrm{T}_{\mathrm{H}}$ 17-based vaccine design for prevention of Streptococcus pneumoniae colonization. Cell Host Microbe 2011;9:158-65.
26. Miller ML, Gao G, Pestina T, Persons D, Tuomanen E. Hypersusceptibility to invasive pneumococcal infection in experimental sickle cell disease involves platelet-activating factor receptor. J Infect Dis 2007;195:581-4.

27. Jonker MA, Hermsen JL, Gomez FE, Sano Y, Kudsk KA. Injury induces localized airway increases in pro-inflammatory cytokines in humans and mice. Surg Infect (Larchmt) 2011;12:49-56.

28. Wanderer AA. Rationale for IL-1 $\beta$ targeted therapy for ischemia-reperfusion induced pulmonary and other complications in sickle cell disease. J Pediatr Hematol Oncol 2009;31:537-8.

29. Kabbur PM, Carson WF 4th, Guernsey L, Secor ER Jr, Thrall RS, Schramm CM. Interleukin-10 does not mediate inhalational tolerance in a chronic model of ovalbumin-induced allergic airway disease. Cell Immunol 2006;239:67-74. 